\title{
Corrosion Prevention of Cast Iron Industrial Water Pipes: A Preliminary Comparative Study of Hexamine and Aniline Inhibitors
} Hayder Mohammed Issa ${ }^{1 *}$ Azad H. Alshatteri ${ }^{2}$

${ }^{1}$ College of Human Sciences, University of Garmian, Kalar, Al- Sulaimaniyah, Kurdistan Region, Iraq ${ }^{2}$ Chemistry Dept., Education College, University of Garmian, Kalar, Al- Sulaimaniyah, Kurdistan Region, Iraq

*Corresponding author. Email: hayder.mohammed@garmian.edu.krd

\section{Abstract}

Using cast iron pipes in various industrial and water systems is experiencing a major problem of corrosion occurrence. Hence the operation and maintenance of these pipes become costly and infeasible. Corrosion inhibitors have a great role in decreasing pipes corrosion rate. In this study, the inhibition effect by applying two inhibitors of hexamethylenetetramine (hexamine) and aniline on cast iron pipes was studied. Experimental measurements of the corrosion behavior of cast iron pipes was thoroughly examined in three aqueous salt solutions of $2 \% \mathrm{NaCl}, 2 \% \mathrm{Na}_{2} \mathrm{SO}_{4}$ and $2 \% \mathrm{CaCO}_{3}$. The corrosion inhibition efficiency of the cast iron pipes by aniline or hexamine in the three aqueous salt aqueous solutions was investigated at constant temperature and for different time intervals. Corrosion rates of the pipes were determined using weight loss technique. It has been found that, for the corrosion of cast iron pipes, a satisfactory inhibition efficiency is observed for a concentration close to $150 \mathrm{ppm}$ hexamine and $150 \mathrm{ppm}$ aniline over the whole aqueous salt solutions tested in the work. The results showed that at the same inhibitor concentration and temperature, aniline exhibits higher inhibition corrosion efficiency on cast iron pipes than the efficiency achieved by hexamine.

Keywords: cast iron pipes; corrosion inhibitors, hexamethylenetetramine; aniline; aqueous salt solution

\section{Introduction}

Cast iron as an alloy is widely used for water carrying purposes besides mild steel and other metals. Cast iron is also widely used in industrial water piping systems for more than one century. In the past, in industry the pipes were used especially for carrying water were made of cast iron (Mohebbi and Li 2011). The extent and cost of damage caused by corrosion in cast iron water pipes has been rising during recent decades (Mehra and Soni 2002). The use of cast iron in industrial water pipes and potable water distribution systems is essentially suffering from an inevitable corrosion problems 
(Atkinson et al. 2002). Actually, this corrosion phenomenon is now considered as the main problem facing cast iron water pipes operation and maintenance in industry, potable water distribution, and wastewater systems (Agatemor and Okolo 2008; Daneshvar-Fatah et al. 2013; Hasan and Sadek 2014; Li et al. 2016; Liang et al. 2013). The corrosion of cast iron pipes is actually varied regarding both material quality and purpose of using (Yang et al. 2012). Corrosion leads to deterioration and failures of those industrial pipes and equipment made of cast iron (Essa 2006; Kuźnicka 2009). The high cost of occurring corrosion in industry and water systems shows the need to improved corrosion measurement and prevention schemes (Reynaud 2010).

Among available solutions of corrosion in engineering materials, inhibitors were found to be of high practical importance, in minimizing metallic waste (Collins et al. 1993). Corrosion protection aims to improve performance of pipes metal (Dwivedi et al. 2017). Methods of Corrosion control are needed to be properly selected according to environment and operational conditions of pipes and equipment (Mannivanan et al. 2012). Corrosion inhibitors are employed as it has been observed the absence of corrosion inhibitors leads always to an exponential increase in corrosion rate of pipe metals (Barmatov et al. 2015). Corrosion inhibitors are commonly single organic components, but mixtures of solvents-compound or compound-surfactant are regularly used (Finšgar and Jackson 2014; Hill and Jones 2003). Various nitrogen or sulfurcontaining organic compounds have been used as corrosion inhibitors (Al-Rawajfeh and Al-Shamaileh 2007; Ebenso et al. 2001; Ekpe et al. 1995; Fathima Sabirneeza et al. 2015; Hosseini et al. 2003). The mechanism of corrosion inhibition in surface processes involves adsorption of the inhibitor organic compounds on the metal surface that needed to be protected (Zhu et al. 2015). Inhibition efficiency of organic compounds is usually depends on inhibitor molecular size and the mode of interaction with metal surface (Shirazi et al. 2017).

The corrosion of cast iron in acidic and alkaline mediums was studied in several previous works (Osarolube et al. 2008; Simsek et al. 2010). These studies figured out aqueous salt solutions, at high salt concentrations such as $3.0 \mathrm{M}$, are the most corrosive for cast iron metal. The corrosion behavior was characterized by two factors of salt and oxygen dissolved in aqueous solutions (Shakir et al. 2018). Many previous works have studied hexamine (hexamethylenetetramine) and aniline or their derivatives inhibition properties to protect metals in different acidic and alkaline mediums. The studies were made for diverse metals and alloys such as copper and iron (Benchikh et al. 2009; Essa 2007; Khaled and Hackerman 2004; Vashi and Naik 2010). It has been found that low 
molecular mass and high water solubility amines such as hexamine produce higher adsorption and corrosion prevention (Bayol et al. 2007). Aniline and its derivatives are also used as inhibitors as they found to inhibit metal corrosion, especially iron with great extent (Jeyaprabha et al. 2006).

As any obtained information on the rate at which corrosion initiates and progress in cast iron pipes is considered to be important for the attempts to control or reduce the damage caused by corrosion. Moreover, the controlling of deterioration and failures become extremely challenging without a well understanding of the cast iron pipes corrosion. In this work, the aim is to investigate the inhibition effect of aniline and hexamine on cast iron pipes in three different aqueous salt solutions $\mathrm{NaCl}, \mathrm{Na}_{2} \mathrm{SO}_{4}$, and $\mathrm{CaCO}_{3}$. The corrosion rate of cast iron pipe was experimentally determined using weight loss method with and without inhibitors presence.

\section{Materials and Method}

2.1. Material Preparation and Weight Loss Measurement Specimens were cut from cast iron water pipes of outer diameter $24 \mathrm{~mm}$, a thickness of $2 \mathrm{~mm}$. The arrangement of the cast iron alloy testing was as coupon specimen of $2 \times 2 \mathrm{~cm}^{2}$ and thickness $0.2 \mathrm{~cm}$, a hole was drilled diameter $0.05 \mathrm{~cm}$ at the upper edge. The surface of specimens were cleaned, degreased in benzene, washed using 50\% acetone, dried, marked and weighed to a constant weight before exposing to the corrosive medium. The specimens were suspended by a glass hook in a beaker filled with test solution, for different duration of immersion 72, 120, 168, 240, and 288 hours in three aqueous salt corrosive mediums. All test solutions were prepared from analytical grade reagents and double - distilled water. The testing aqueous salt solutions are $2 \% \mathrm{NaCl}, 2 \% \mathrm{Na}_{2} \mathrm{SO}_{4}$ and $2 \% \mathrm{CaCO}_{3}$ at room temperature. At the end of each exposure time, the specimens were removed, cleaned, dried and weighed. All specimen metal surfaces, including the edges, were abraded to original ground using grit silicon carbide papers to remove any coated layer to prevent corrosion to pipes like galvanized zinc layer. Figure 1 (a) shows the clean surface of specimen cast iron pipe, as can be seen in Figure 1 (b), the specimen cast iron pipe with a localized corrosion condition is being evident on pipe surface after 288-hour (12 days) immersion in $2 \% \mathrm{NaCl}$ solution. 


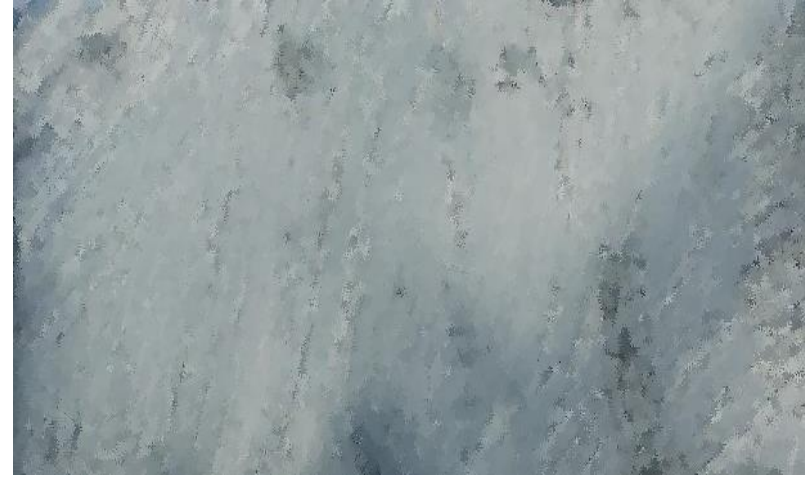

(a)

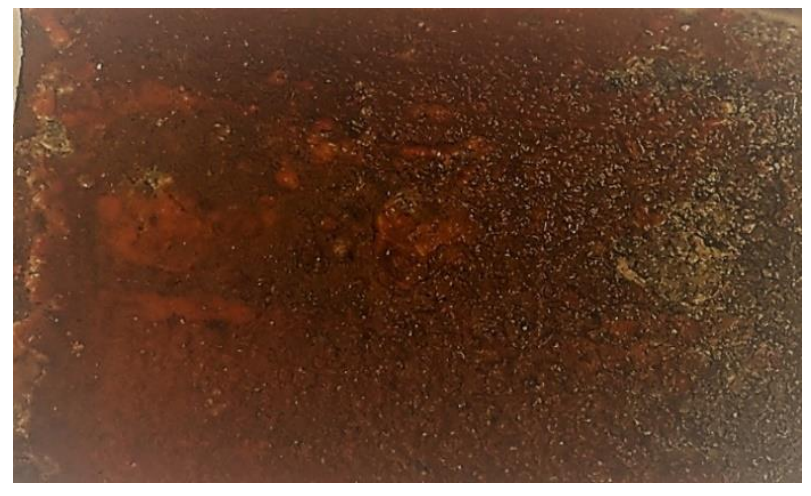

(b)

Figure 1.a. The clean surface of specimen cast iron pipe, Figure 1.b. The specimen cast iron pipe with localized corrosion on the surface after 12 days immersion in $2 \% \mathrm{NaCl}$ solution.

The chemicals aniline and hexamine were used as corrosion inhibitors for this investigation. The inhibitors concentrations were $150 \mathrm{ppm}$ were prepared in $2 \% \mathrm{NaCl}$, $2 \% \mathrm{Na}_{2} \mathrm{SO}_{4}$ and $2 \% \mathrm{CaCO}_{3}$ aqueous salt solutions at $25 \pm 2{ }^{\circ} \mathrm{C}$. The molecular structures of the inhibitors used are displayed in Figure 2 (a), and (b).

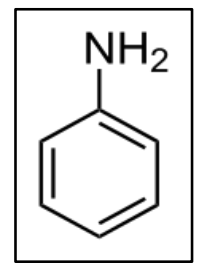

(a)

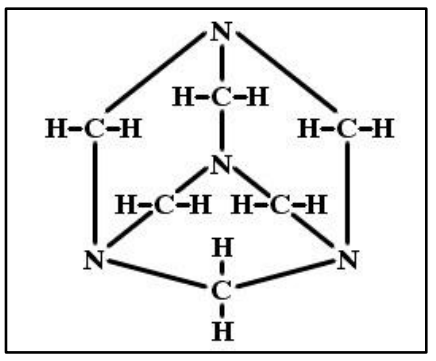

(b)

Figure 2.a. the molecular structure of the aniline inhibitor. Figure 2.b. the molecular structure of the hexamethylenetetramine (hexamine) inhibitor.

\subsection{Pipe Metal Analysis}

The cast iron pipe specimens were analyzed using ICP-OES: Spectro Arcos in the chemical laboratory at University of Garmian. The chemical composition of the cast iron pipes is shown in Table 1. The instrument conditions used were: Spray chamber is Scott spray; Nebulizer: crossflow; RF power/W: 1400; pump speed: 30 RPM; Coolant flow (L/min): 14; Auxiliary flow (L/min): 0.9; nebulizer gas flow (L/min): 0.8; Preflush (s): 40; Measure time (s): 28; replicate measurement: 3; argon gas (purity $\geq 99.99$ ); multielements stock solutions containing $1000 \mathrm{mg} / \mathrm{L}$ were obtained from Bernd Kraft (Bernd Kraft GmbH, Duisburg, Germany); standard solutions were diluted by several dilution in $0.5 \%$ nitric acid as diluent. 
Table 1. Chemical composition of cast iron pipes used for water carrying

\begin{tabular}{|l|c|c|c|c|c|c|c|c|c|c|c|}
\hline Component* & $\mathrm{Fe}$ & $\mathrm{Si}$ & $\mathrm{Mn}$ & $\mathrm{S}$ & $\mathrm{Ni}$ & $\mathrm{Cu}$ & $\mathrm{Pb}$ & $\mathrm{Mo}$ & $\mathrm{V}$ & $\mathrm{Mg}$ & $\mathrm{Cr}$ \\
\hline $\begin{array}{l}\text { Wt. } \\
\text { Percentage } \\
(\%)\end{array}$ & 95.00 & 1.00 & 1.70 & 0.02 & 0.06 & 0.06 & 0.01 & 0.03 & 0.06 & 0.02 & 0.14 \\
\hline
\end{tabular}

*The rest is carbon $\mathrm{C}$.

\subsection{Inhibition Efficiency and Degree of Surface Coverage Calculations}

After the weight loss of cast iron specimens, efficiency was determined as the difference in the weight before and after each exposure time in test aqueous salt solutions for each inhibitor. The values of percentage corrosion inhibition efficiency of aniline and hexamine inhibitors in the three investigated aqueous salt solutions for the various immersion periods was calculated using the following equation that obtained from literature (Abiola et al. 2013; James and Akaranta 2011; Rafiquee et al. 2009). The definition of each symbol in the following equation is presented in the nomenclature at the end of this paper.

$I E \%=\left(1-\frac{W_{i}}{W_{n}}\right) * 100 \%$

The degree of surface coverage, $\theta$ was determined by the following equation (Daoud et al. 2015; Sirajunnisa et al. 2014);

$\theta=\left(1-\frac{W_{i}}{W_{n}}\right)$

\subsection{Corrosion Rate Calculations}

The corrosion rate of cast iron in different aqueous salt solution mediums was determined for different immersion period from weight loss using the equation below. The same corrosion rate (CR) equation was used for various metals and solutions (Anand and Balasubramanian 2011; Singh and Quraishi 2015):

$$
C_{R}=\frac{87.6 \mathrm{~W}}{A t D}
$$

Where $\mathrm{W}$ (in $\mathrm{mg}$ ) is the weight loss and calculated as follows:

$W=W_{0}-W_{t}$

\section{Results and Discussion}

\subsection{Morphology of Corroded Metal Surface}


The corroded metal surface has been changed in appearance and its color was turned into brown for all the specimens of cast iron pipes. As shown in Figure 1 typical changes in the corrosion products on a specimen after 12 days exposure in $2 \% \mathrm{NaCl}$. In general, the look of the corroded surface of cast iron specimens was the same for all the investigated aqueous salt solutions, but the thickness of corrosion product varies with exposure time. The localized corrosion occurred on specimen surface is the main form of corrosion of water used cast iron pipes.

\subsection{Weight Loss and Corrosion Rates}

Results obtained from weight loss and corrosion rate of cast iron pipe specimens in a $2 \%$ $\mathrm{NaCl}, 2 \% \mathrm{Na}_{2} \mathrm{SO}_{4}$, and $2 \% \mathrm{CaCO}_{3}$ solutions at $25 \pm 2{ }^{\circ} \mathrm{C}$ are showed in Tables 2 and 3. From which it can be observed that the weight loss for specimens in the three solutions increases with time, in consequence, the corrosion rate is also increases with time. The corrosion rate of cast iron specimens in the test solutions was calculated from the decrease in weight loss by applying equations 3 and 4 .

Table 2. Weight loss $\left(\mathrm{mg} / \mathrm{cm}^{2}\right)$ of the cast iron specimens in 3 aqueous salt solutions of $2 \% \mathrm{NaCl}, 2 \%$ ppm $\mathrm{Na}_{2} \mathrm{SO}_{4}$ and $2 \%$ ppm $\mathrm{CaCO}_{3}$ at $25 \pm 2^{\circ} \mathrm{C}$ and for different time intervals.

\begin{tabular}{|l|c|c|c|c|c|c|}
\hline Time (hr.) & 24 & 72 & 120 & 168 & 240 & 288 \\
\hline $\mathrm{NaCl}$ & 0.138 & 0.422 & 0.774 & 1.181 & 1.689 & 1.882 \\
\hline $\mathrm{Na}_{2} \mathrm{SO}_{4}$ & 0.059 & 0.248 & 0.493 & 0.731 & 0.974 & 1.134 \\
\hline $\mathrm{CaCO}_{3}$ & 0.057 & 0.191 & 0.322 & 0.484 & 0.668 & 0.748 \\
\hline
\end{tabular}

Table 3. Corrosion rates (mmpy) of the cast iron specimens in three aqueous salt solutions of $2 \% \mathrm{NaCl}$, $2 \%$ ppm $\mathrm{Na}_{2} \mathrm{SO}_{4}$ and $2 \%$ ppm $\mathrm{CaCO}_{3}$ at $25 \pm 2^{\circ} \mathrm{C}$ and for different time intervals.

\begin{tabular}{|l|c|c|c|c|c|c|}
\hline Time (hr.) & 24 & 72 & 120 & 168 & 240 & 288 \\
\hline $\mathrm{NaCl}$ & 0.0690 & 0.0704 & 0.0774 & 0.0844 & 0.0845 & 0.0784 \\
\hline $\mathrm{Na}_{2} \mathrm{SO}_{4}$ & 0.0295 & 0.0414 & 0.0493 & 0.0522 & 0.0487 & 0.0473 \\
\hline $\mathrm{CaCO}_{3}$ & 0.0284 & 0.0318 & 0.0322 & 0.0346 & 0.0334 & 0.0312 \\
\hline
\end{tabular}

For the specimens in $2 \% \mathrm{NaCl}$ solution, the corrosion rate seems to follow a specific trend and it appears to increase with time. But this increase is more drastic and then tends to be less at longer exposure time. For the specimens in $2 \% \mathrm{Na}_{2} \mathrm{SO}_{4}$ solution, the corrosion rate seems to establish a different trend as it decreases at the higher exposure time. For the specimens in $2 \% \mathrm{CaCO}_{3}$ solution, the average corrosion rate is close at exposure times longer than $120 \mathrm{hr}$. Based on the analysis of the corrosion rate results obtained from the three aqueous salt solutions it can be understand that the localized 
corrosion behavior of cast iron water pipes is the primary form of corrosion degradation. The intensity of the localized corrosion depends on the extent of time exposure. From Tables 2 and 3, where the weight loss and corrosion rate values were listed, it can be observed from corrosion rate in mmpy of cast iron specimens in the three tested aqueous salt solutions are in the order of $\mathrm{NaCl}>\mathrm{Na}_{2} \mathrm{SO}_{4}>\mathrm{CaCO}_{3}$ during time of exposure of 288 hours.

\subsection{Effect of Corrosion Inhibitors}

The weight loss measurements were carried out of cast iron specimens with aniline and hexamine corrosion inhibitors concentrations of $150 \mathrm{ppm}$ separately. The exposure time was ranging from 24 to 288 hours to study the effect of inhibitor presence and immersion time on the corrosion rate of cast iron water pipes at $25 \pm 2^{\circ} \mathrm{C}$ as seen in Table 4 and 5. It was found that with use of $150 \mathrm{ppm}$ concentration of aniline and hexamine inhibitors causes decreasing of weight loss in all the studied aqueous salt solutions as displayed in Figure 3 to 5.

Figure 3 shows the results of specimen weight loss produced from corrosion of cast iron pipes for different exposure time in three conditions of $2 \% \mathrm{NaCl}$ aqueous salt solution. In one these conditions $150 \mathrm{ppm}$ of hexamine inhibitor was added and in another, a 150 ppm aniline was added to the solution.

As illustrated in Figure 3, the amount of weight loss was decreased considerably when $150 \mathrm{ppm}$ hexamine was added to $\mathrm{NaCl}$ solution. The weight loss of cast iron specimens was more significantly decreased when $150 \mathrm{ppm}$ aniline was added to the solution. The same effect was noticed for the other two aqueous solutions of $2 \% \mathrm{Na}_{2} \mathrm{SO}_{4}$ and $2 \%$ $\mathrm{CaCO}_{3}$ as presented in Figures 4 and 5 for the exposure time ranges from 24 hr. to 288 hr. 


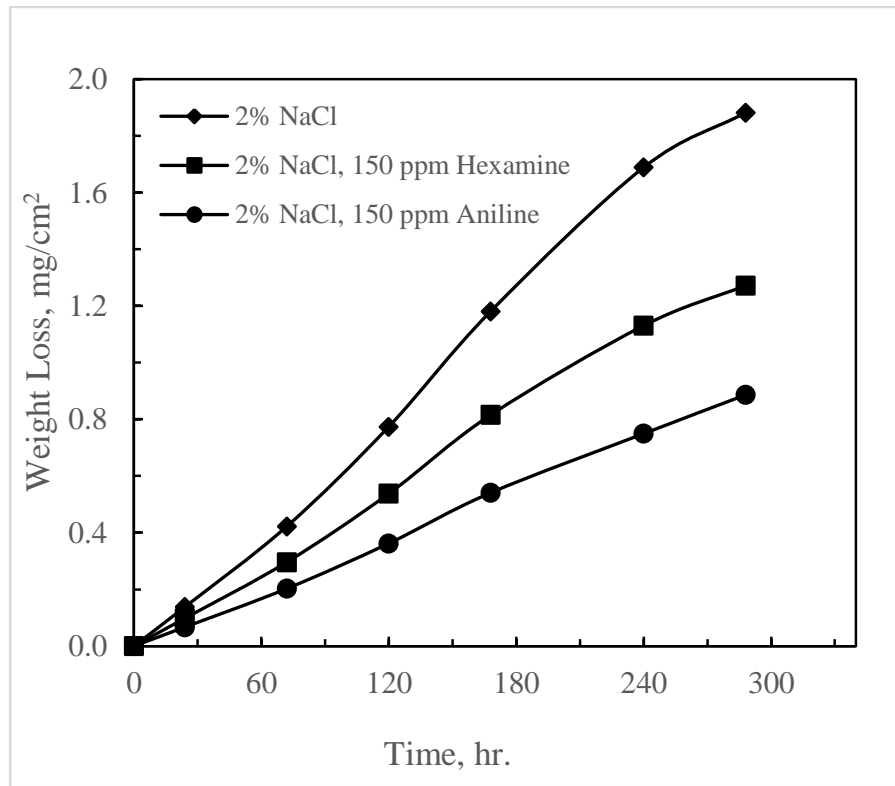

Figure 3. Variation of specific weight loss with time of cast iron specimens in $150 \mathrm{ppm}$ Aniline and $150 \mathrm{ppm}$ hexamine inhibitors added to $2 \% \mathrm{NaCl}$ solution at $25 \pm 2^{\circ} \mathrm{C}$.

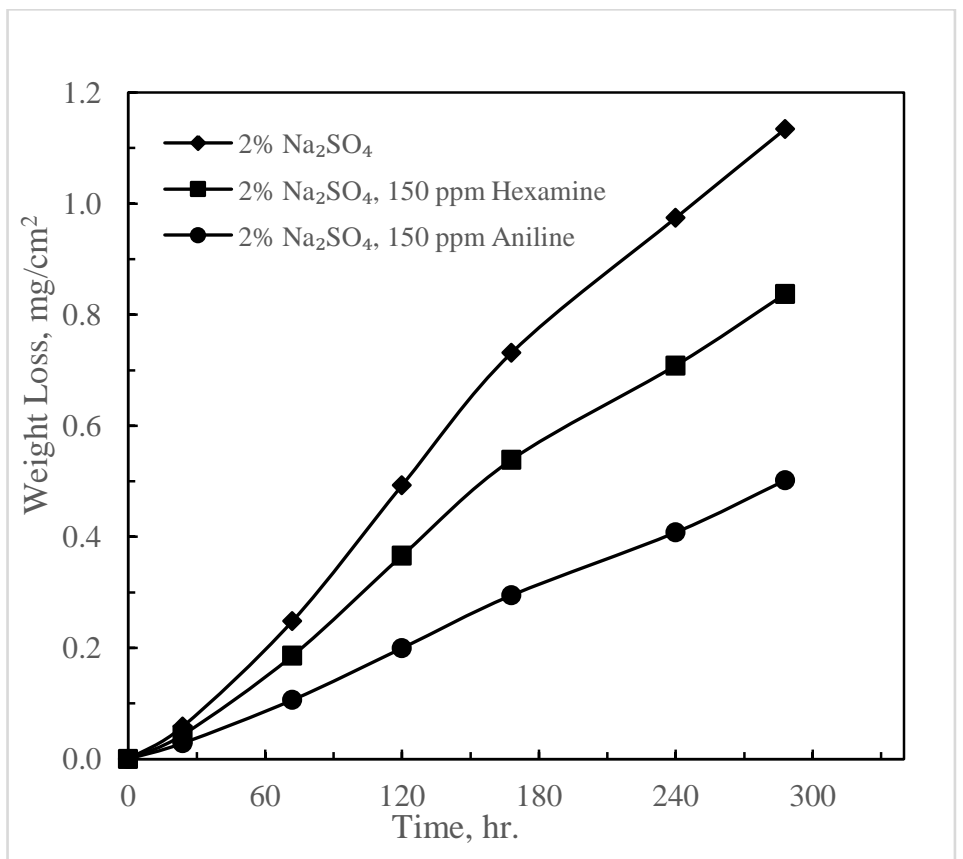

Figure 4. Variation of specific weight loss with time of cast iron specimens in $150 \mathrm{ppm}$ Aniline and $150 \mathrm{ppm}$ hexamine inhibitors added to $2 \% \mathrm{Na}_{2} \mathrm{SO}_{4}$ solution at $25 \pm 2^{\circ} \mathrm{C}$. 


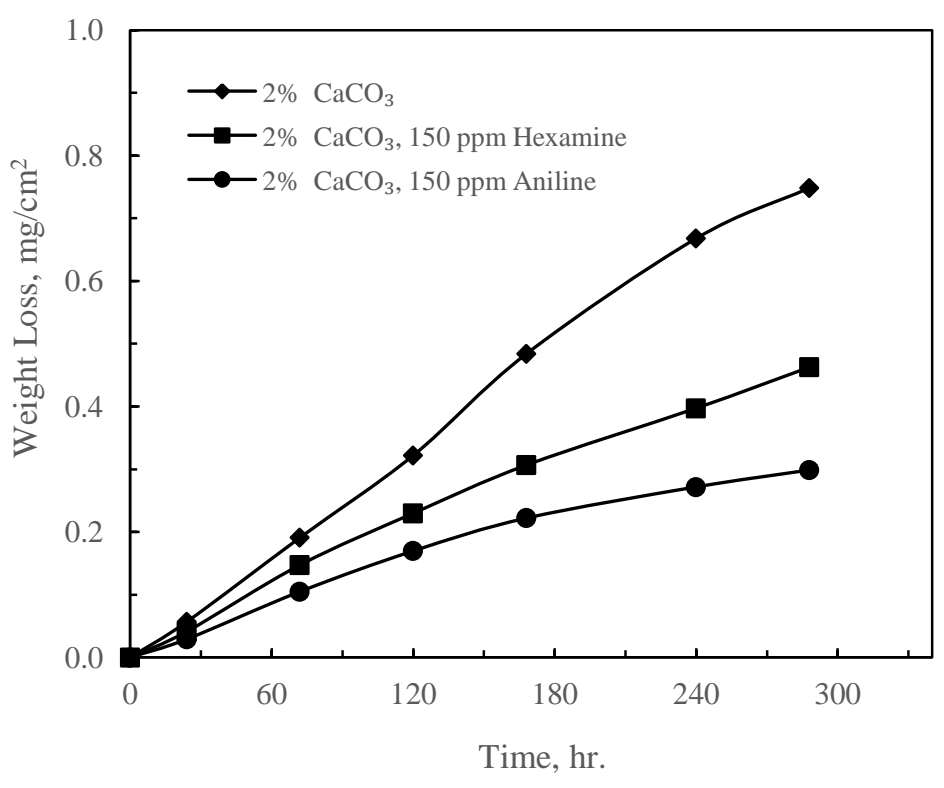

Figure 5. Variation of specific weight loss with time of cast iron specimens in $150 \mathrm{ppm}$ Aniline and $150 \mathrm{ppm}$ hexamine inhibitors added to $2 \% \mathrm{CaCO}_{3}$ solution at $25 \pm 2^{\circ} \mathrm{C}$.

From Table 4 it was found that with increase in exposure time from 24 to 288 hours, the weight loss decreased and hence the inhibition efficiency increased from $28.95 \%$ to $32.41 \%$ when $150 \mathrm{ppm}$ hexamine was added to the solution of $2 \% \mathrm{NaCl}$ (surface coverage increased from 0.289 to 0.324 ). The increase ranges of efficiency of $2 \%$ $\mathrm{Na}_{2} \mathrm{SO}_{4}$ and $2 \% \mathrm{CaCO}_{3}$ were (from $25.46 \%$ to $26.16 \%$ ) and (from $27.37 \%$ to $35.38 \%$ ).

In terms of metal protection, these results indicate that adding $150 \mathrm{ppm}$ of hexamine is the satisfactory concentration to develop acceptable corrosion prevention for cast iron pipe specimens in the investigated salt solutions. The behavior of hexamine inhibitor most probably results from adsorption on metal surface is suitable with this concentration of hexamine and therefore the inhibition efficiency was reasonable.

Table 4 shows the results of $150 \mathrm{ppm}$ aniline added to the tested aqueous salt solutions. It can be observed that the corrosion rate reduced during with time interval from 24 to 288 hours for $2 \% \mathrm{NaCl}, 2 \% \mathrm{Na}_{2} \mathrm{SO}_{4}$, and $2 \% \mathrm{CaCO}_{3}$. The reduction of corrosion rate increases higher than that achieved by $150 \mathrm{ppm}$ hexamine. The reason of this difference is most possibly due to the adsorption behavior of anions the electrolyte of aniline at the electrode surface (Luo et al. 1998). 
Table 4. Corrosion parameters, obtained from weight loss measurements for cast iron specimens in three aqueous salt solutions of $2 \% \mathrm{NaCl}, 2 \% \mathrm{Na}_{2} \mathrm{SO}_{4}$ and $2 \% \mathrm{CaCO}_{3}$ at $25 \pm 2{ }^{\circ} \mathrm{C}$, containing $150 \mathrm{ppm}$ hexamine inhibitor for different time intervals.

\begin{tabular}{|c|c|c|c|}
\hline $\begin{array}{c}\text { Exposure time } \\
(\mathrm{hr} .)\end{array}$ & $\begin{array}{c}\text { Corrosion rate } \\
(\mathrm{mmpy})\end{array}$ & $\begin{array}{c}\text { Inhibition efficiency } \\
(\%)\end{array}$ & $\begin{array}{c}\text { Surface coverage } \\
(\theta)\end{array}$ \\
\hline $2 \% \mathrm{NaCl}$ & \multicolumn{3}{|l|}{} \\
\hline 24 & 0.0490 & 28.95 & 0.289 \\
\hline 72 & 0.0494 & 29.86 & 0.299 \\
\hline 120 & 0.0538 & 30.52 & 0.305 \\
\hline 168 & 0.0583 & 30.96 & 0.310 \\
\hline 240 & 0.0565 & 33.05 & 0.331 \\
\hline 288 & 0.0530 & 32.41 & 0.324 \\
\hline $2 \% \mathrm{Na}_{2} \mathrm{SO}_{4}$ & \multicolumn{3}{|l}{} \\
\hline 24 & 0.0220 & 25.46 & 0.255 \\
\hline 72 & 0.0310 & 25.13 & 0.251 \\
\hline 120 & 0.0366 & 25.70 & 0.257 \\
\hline 168 & 0.0385 & 26.31 & 0.263 \\
\hline 240 & 0.0354 & 27.27 & 0.273 \\
\hline 288 & 0.0349 & 26.16 & 0.262 \\
\hline $2 \% \mathrm{CaCO}_{3}$ & \multicolumn{3}{|l}{} \\
\hline 24 & 0.0206 & 27.37 & 0.274 \\
\hline 72 & 0.0246 & 22.83 & 0.228 \\
\hline 120 & 0.0230 & 28.66 & 0.287 \\
\hline 168 & 0.0219 & 36.65 & 0.366 \\
\hline 240 & 0.0209 & 37.53 & 0.375 \\
\hline 288 & 0.0202 & 35.38 & 0.354 \\
\hline
\end{tabular}

From the results presented in Table 4, it was found with the weight loss increases with time for all three solutions and the corrosion rate remains at certain levels with time for $\mathrm{NaCl}$ and $\mathrm{Na}_{2} \mathrm{SO}_{4}$ solutions. However, for $2 \% \mathrm{CaCO}_{3}$ solution, the corrosion rate drops relatively after 168 hours. This declining is perhaps because of the stability of ferric oxide film that formed after corrosion occurrence. The phenomena is known for corrosion inhibitor behavior of anions in aqueous solutions (Xu et al. 2017). In general, it is noticed that the corrosion rate is highly reduced in the solutions contain hexamine or aniline inhibitor. The reduction occurs due to the inhibitor protection for the metals by preventing the direct contact between metals surface and corrosive anions. In the same time, the reduction is also made by decreasing plenty of cations on the metal surface. At $25{ }^{0} \mathrm{C} \pm 2$ and 240 hours with presence $150 \mathrm{ppm}$ hexamine and $150 \mathrm{ppm}$ aniline, the 
corrosion rate of $2 \% \mathrm{NaCl}$ solution was lessened to 0.0565 and $0.0375 \mathrm{mmpy}$ respectively. While for $\mathrm{Na}_{2} \mathrm{SO}_{4}$ and $\mathrm{CaCO}_{3}$ solutions, same thing happened at varying rates of the corrosion. The two anions are reported to have a significant influence on the corrosion characteristics of cast iron are chloride and sulfate ions (Ekpe et al. 2001).

Table 5. Corrosion parameters obtained from weight loss measurements for cast iron specimens in three aqueous salt solutions of $2 \% \mathrm{NaCl}, 2 \% \mathrm{Na}_{2} \mathrm{SO}_{4}$ and $2 \% \mathrm{CaCO}_{3}$ at $25 \pm 2^{\circ} \mathrm{C}$, containing $150 \mathrm{ppm}$ aniline inhibitor for different time intervals.

\begin{tabular}{|c|c|c|c|}
\hline $\begin{array}{c}\text { Exposure time } \\
(\mathrm{hr} .)\end{array}$ & $\begin{array}{c}\text { Corrosion rate } \\
(\mathrm{mmpy})\end{array}$ & $\begin{array}{c}\text { Inhibition efficiency } \\
(\%)\end{array}$ & $\begin{array}{c}\text { Surface coverage } \\
(\theta)\end{array}$ \\
\hline $2 \% \mathrm{NaCl}$ & \multicolumn{3}{|l|}{} \\
\hline 24 & 0.0335 & 51.50 & 0.515 \\
\hline 72 & 0.0338 & 52.00 & 0.520 \\
\hline 120 & 0.0362 & 53.20 & 0.532 \\
\hline 168 & 0.0386 & 54.20 & 0.542 \\
\hline 240 & 0.0375 & 55.62 & 0.556 \\
\hline 288 & 0.0369 & 52.90 & 0.529 \\
\hline $2 \% \mathrm{Na}_{2} \mathrm{SO}_{4}$ & \multicolumn{3}{|l|}{} \\
\hline 24 & 0.0144 & 51.08 & 0.511 \\
\hline 72 & 0.0177 & 57.20 & 0.572 \\
\hline 120 & 0.0200 & 59.50 & 0.595 \\
\hline 168 & 0.0211 & 59.70 & 0.597 \\
\hline 240 & 0.0204 & 58.12 & 0.581 \\
\hline 288 & 0.0209 & 55.77 & 0.558 \\
\hline $2 \% \mathrm{CaCO}_{3}$ & \multicolumn{3}{|l}{} \\
\hline 24 & 0.0145 & 48.79 & 0.488 \\
\hline 72 & 0.0175 & 45.06 & 0.451 \\
\hline 120 & 0.0170 & 47.30 & 0.473 \\
\hline 168 & 0.0159 & 54.12 & 0.541 \\
\hline 240 & 0.0136 & 59.31 & 0.593 \\
\hline 288 & 0.0124 & 60.08 & 0.601 \\
\hline \multicolumn{3}{|l|}{}
\end{tabular}

The exposure time effect on cast iron corrosion rate from 24 to 288 hours was also explored in this work. For both hexamine and aniline inhibitor in $2 \% \mathrm{NaCl}$ solution, the inhibition efficiency enhanced (from $28.95 \%$ to $32.41 \%$ ), and (from $51.50 \%$ to 52.90 $\%)$ respectively.

The increase in inhibition efficiency at longer immersion time is due to anion kinetics in aqueous solutions of strengthening of adsorption that mentioned above. The immersion time with corrosion inhibitors aniline and hexamine scores highest inhibition efficiency 
of cast iron specimens in $2 \% \mathrm{NaCl}, 2 \% \mathrm{Na}_{2} \mathrm{SO}_{4}$ and $2 \% \mathrm{CaCO}_{3}$ at 288 hours as given in Tables 3 and 4.

As a result, the inhibition increased as more inhibitor molecules are adsorbed on the metal surface reduces the surface area available for the attack of the aggressive ions from the salt solution. Inhibition efficiency showed remarkable improvement with addition of $150 \mathrm{ppm}$ to $2 \% \mathrm{CaCO}_{3}$ probably for the same reason mentioned above.

\section{Conclusions}

The inhibition of corrosion of cast iron alloy by an addition of $150 \mathrm{ppm}$ hexamine and $150 \mathrm{ppm}$ aniline was performed efficiently in salts solutions of $2 \% \mathrm{NaCl}, 2 \% \mathrm{Na}_{2} \mathrm{SO}_{4}$ and $2 \% \mathrm{CaCO}_{3}$ at $25 \pm 2{ }^{\circ} \mathrm{C}$.

The aniline showed more effective inhibition efficiency than the hexamine. In $2 \% \mathrm{NaCl}$ solution the corrosion rate of cast iron pipes was higher than $2 \% \mathrm{Na}_{2} \mathrm{SO}_{4}$ and $2 \% \mathrm{CaCO}_{3}$ solutions.

Generally, in aqueous salt solutions, the corrosion rate of cast iron alloy appears to be a function of dissolved salt type, inhibitor type and immersion time.

The work described here lead us to expect the using aniline as a corrosion inhibitor rather than hexamine in prevention the cast iron corrosion in industry, where cast iron pipes still implemented to carry aqueous salt solutions.

\section{Nomenclature}
A the area of the specimen $\left(\mathrm{cm}^{2}\right)$,
$\mathrm{C}_{\mathrm{R}}$ the corrosion rate (CR) of cast iron (mmpy),
$\mathrm{t}$ the exposure time $(\mathrm{h})$,
D the density of cast iron $\left(\mathrm{g} / \mathrm{cm}^{3}\right)$
IE\% the inhibition efficiency (\%)
$\theta \quad$ the surface coverage (-)
W weight loss (mg),
$\mathrm{W}_{\mathrm{i}}$ the weight loss of cast iron in the corrodent - inhibitor system (mg),
$\mathrm{W}_{\mathrm{n}}$ the weight loss of cast iron in the corrodent (blank) (mg),
$\mathrm{W}_{0}$ the weight loss of cast iron in the corrodent (blank) at exposure time $0(\mathrm{mg})$,
$\mathrm{W}_{\mathrm{t}}$ the weight loss of cast iron in the corrodent (blank) at the end of exposure time (mg), 


\section{References}

Abiola O, Aliyu A, Phillips A, Ogunsipe A (2013) The effects of Phyllanthus amarus extract on corrosion and kinetics of corrosion process of aluminum in $\mathrm{HCl}$ solution Journal of Materials and Environmental Science 4:370-373

Agatemor C, Okolo PO (2008) Studies of corrosion tendency of drinking water in the distribution system at the University of Benin The Environmentalist 28:379-384 doi:10.1007/s10669-007-9152-2

Al-Rawajfeh AE, Al-Shamaileh EM (2007) Inhibition of corrosion in steel water pipes by ammonium pyrrolidine dithiocarbamate (APDTC) Desalination 206:169-178 doi:https://doi.org/10.1016/j.desal.2006.02.065

Anand B, Balasubramanian V (2011) Corrosion Behaviour of Mild Steel in Acidic Medium in Presence of Aqueous Extract of Allamanda Blanchetii E-Journal of Chemistry 8 doi:10.1155/2011/345095

Atkinson K, Whiter JT, Smith PA, Mulheron M (2002) Failure of small diameter cast iron pipes Urban Water 4:263-271 doi:https://doi.org/10.1016/S14620758(02)00004-3

Barmatov E, Hughes T, Nagl M (2015) Efficiency of film-forming corrosion inhibitors in strong hydrochloric acid under laminar and turbulent flow conditions Corros Sci 92:85-94 doi:https://doi.org/10.1016/j.corsci.2014.11.038

Bayol E, Kayakırılmaz K, Erbil M (2007) The inhibitive effect of hexamethylenetetramine on the acid corrosion of steel Mater Chem Phys 104:7482 doi:https://doi.org/10.1016/j.matchemphys.2007.02.073

Benchikh A, Aitout R, Makhloufi L, Benhaddad L, Saidani B (2009) Soluble conducting poly(aniline-co-orthotoluidine) copolymer as corrosion inhibitor for carbon steel in $3 \% \quad \mathrm{NaCl} \quad$ solution Desalination 249:466-474 doi:https://doi.org/10.1016/j.desal.2008.10.024

Collins WD, Weyers RE, Al-Qadi IL (1993) Chemical Treatment of Corroding Steel Reinforcement After Removal of Chloride-Contaminated Concrete CORROSION 49:74-88 doi:10.5006/1.3316037

Daneshvar-Fatah F, Mostafaei A, Hosseinzadeh-Taghani R, Nasirpouri F (2013) Caustic corrosion in a boiler waterside tube: Root cause and mechanism Eng Failure Anal 28:69-77 doi:https://doi.org/10.1016/j.engfailanal.2012.09.010 
Daoud D, Douadi T, Hamani H, Chafaa S, Al-Noaimi M (2015) Corrosion inhibition of mild steel by two new S-heterocyclic compounds in $1 \mathrm{M} \mathrm{HCl}$ : Experimental and $\begin{array}{lllll}\text { computational study } & \text { Corros } & \text { Sci } & 94: 21-37\end{array}$ doi:https://doi.org/10.1016/j.corsci.2015.01.025

Dwivedi D, Lepkova K, Becker T (2017) Carbon steel corrosion: a review of key surface properties and characterization methods RSC Advances 7:4580-4610 doi:10.1039/C6RA25094G

Ebenso E, Okafor P, Offiong O, Ita B, Ibok U, Ekpe U (2001) Comparative investigation into the kinetics of corrosion inhibition of aluminium alloy AA 1060 in acidic medium Bull Electrochem 17:459-464

Ekpe U, Okafor P, Ebenso E, Offiong O, Ita B (2001) Mutual effects of thiosemicarbazone derivatives on the acidic corrosion of aluminium Bull Electrochem 17:131-135

Ekpe UJ, Ibok UJ, Ita BI, Offiong OE, Ebenso EE (1995) Inhibitory action of methyl and phenyl thiosemicarbazone derivatives on the corrosion of mild steel in hydrochloric acid Mater Chem Phys 40:87-93 doi:https://doi.org/10.1016/02540584(94)01464-R

Essa H. M., (2006), Removal of Corrosion Product from Inside Heat Exchanger Tubes Used in Topping Unit in Azzawia Refinery/Libya by Chemical Methods, Journal of Corrosion Science and Engineering, 10:1-10

Essa H. M., (2007), The Influence of Corrosion Inhibitor (Hexamine) Concentration on Heat Exchanger Copper Alloy Tubes, Corrosion Rate Journal of Corrosion Science and Engineering, 10:1-10

Fathima Sabirneeza AA, Geethanjali R, Subhashini S (2015) Polymeric Corrosion Inhibitors for Iron and Its Alloys: A Review Chem Eng Commun 202:232-244 doi:10.1080/00986445.2014.934448

Finšgar M, Jackson J (2014) Application of corrosion inhibitors for steels in acidic media for the oil and gas industry: A review Corros Sci 86:17-41 doi:https://doi.org/10.1016/j.corsci.2014.04.044

Hasan BO, Sadek SA (2014) The effect of temperature and hydrodynamics on carbon steel corrosion and its inhibition in oxygenated acid-salt solution Journal of 
Industrial and Engineering Chemistry 20:297-307 doi:https://doi.org/10.1016/j.jiec.2013.03.034

Hill DG, Jones A (2003) An Engineered Approach to Corrosion Control During Matrix Acidizing of HTHP Sour Carbonate Reservoir. Paper presented at the CORROSION 2003, San Diego, California, 2003/1/1/

Hosseini M, Mertens SFL, Arshadi MR (2003) Synergism and antagonism in mild steel corrosion inhibition by sodium dodecylbenzenesulphonate and hexamethylenetetramine $\quad$ Corros $\quad$ Sci $\quad 45: 1473-1489$ doi:https://doi.org/10.1016/S0010-938X(02)00246-9

James A, Akaranta O (2011) Inhibition of corrosion of zinc in hydrochloric acid solution by red onion skin acetone extract Research Journal of Chemical Sciences Vol 1:1

Jeyaprabha C, Sathiyanarayanan S, Venkatachari G (2006) Polyaniline as corrosion inhibitor for iron in acid solutions J Appl Polym Sci 101:2144-2153 doi:10.1002/app.22579

Khaled KF, Hackerman N (2004) Ortho-substituted anilines to inhibit copper corrosion in aerated 0.5 M hydrochloric acid Electrochim Acta 49:485-495 doi:https://doi.org/10.1016/j.electacta.2003.09.005

Kuźnicka B (2009) Erosion-corrosion of heat exchanger tubes Eng Failure Anal 16:2382-2387 doi:https://doi.org/10.1016/j.engfailanal.2009.03.026

Li M, Liu Z, Chen Y, Hai Y (2016) Characteristics of iron corrosion scales and water quality variations in drinking water distribution systems of different pipe materials Water Res 106:593-603 doi:https://doi.org/10.1016/j.watres.2016.10.044

Liang $\mathbf{J}$ et al. (2013) Impact of flow rate on corrosion of cast iron and quality of remineralized seawater reverse osmosis (SWRO) membrane product water Desalination 322:76-83 doi:https://doi.org/10.1016/j.desal.2013.05.001

Luo H, Guan YC, Han KN (1998) Corrosion Inhibition of a Mild Steel by Aniline and Alkylamines in Acidic Solutions CORROSION 54:721-731 doi:10.5006/1.3284891

Mannivanan M, Rajendran S, Prabha AS (2012) Inhibitors for Prevention of Corrosion of Metals in Sea water-An Overview European Chemical Bulletin 1:317-329 doi:http://dx.doi.org/10.17628/ecb.2012.1.317-329 
Mehra R, Soni A (2002) Cast iron deterioration with time in various aqueous salt solutions Bull Mater Sci 25:53-58 doi:10.1007/bf02704595

Mohebbi H, Li CQ (2011) Experimental Investigation on Corrosion of Cast Iron Pipes International Journal of Corrosion 2011:17 doi:10.1155/2011/506501

Osarolube E, Owate I, Oforka N (2008) Corrosion behaviour of mild and high carbon steels in various acidic media Scientific Research and Essay 3:224-228

Rafiquee MZA, Khan S, Saxena N, Quraishi MA (2009) Investigation of some oleochemicals as green inhibitors on mild steel corrosion in sulfuric acid J Appl Electrochem 39:1409-1417 doi:10.1007/s10800-009-9811-8

Reynaud A (2010) 3.02 - Corrosion of Cast Irons A2 - Cottis, Bob. In: Graham M, Lindsay R, Lyon S, Richardson T, Scantlebury D, Stott H (eds) Shreir's Corrosion. Elsevier, Oxford, pp 1737-1788. doi:https://doi.org/10.1016/B978044452787-5.00088-3

Shakir IK, Alsamurraee A-KMA, Saleh SM (2018) Pitting Corrosion Behavior of 304 SS and 316 SS Alloys in Aqueous Chloride and Bromide Solutions Journal of Engineering:53-69\% V 24

Shirazi Z, Keshavarz MH, Esmaeilpour K, Pakniya T (2017) A Novel and Simple Method for the Prediction of Corrosion Inhibition Efficiency without Using Complex Computer Codes Z Anorg Allg Chem 643:2149-2157 doi:10.1002/zaac.201700347

Simsek M et al. (2010) Boronizing Effect on the Corrosion Behaviour of Chilled Cast Iron and AISI 1050 Steel vol 29. doi:10.1515/HTMP.2010.29.4.241

Singh A, Quraishi MA (2015) The extract of Jamun (Syzygium cumini) seed as green corrosion inhibitor for acid media Res Chem Intermed 41:2901-2914 doi:10.1007/s11164-013-1398-3

Sirajunnisa A, Mohamed MF, Subramania A, Venkatraman B (2014) The inhibitive effect of Ziziphus jujuba leaves extract on the alkaline corrosion of aluminium European Journal of Applied Sciences and Technology [EUJAST] Volume 1

Vashi RT, Naik D (2010) Hexamine as Corrosion Inhibitors for Zinc in Phosphoric Acid E-Journal of Chemistry 7: S1-S6 doi:10.1155/2010/402764 
Xu Q, Pang X, Gao K (2017) Effects of anions on corrosion behaviour of carbon steel in simulated groundwater in China Corrosion Engineering, Science and Technology 52:84-89 doi:10.1080/1478422X.2017.1294356

Yang F, Shi B, Gu J, Wang D, Yang M (2012) Morphological and physicochemical characteristics of iron corrosion scales formed under different water source histories in a drinking water distribution system Water Res 46:5423-5433 doi:https://doi.org/10.1016/j.watres.2012.07.031

Zhu Y, Free ML, Yi G (2015) Electrochemical measurement, modeling, and prediction of corrosion inhibition efficiency of ternary mixtures of homologous surfactants in salt solution Corros $\quad$ Sci $98: 417-429$ doi:https://doi.org/10.1016/j.corsci.2015.05.050 